\title{
Fatty acid composition and docosahexaenoic acid (DHA) content of the heterotrophic dinoflagellate Oxyrrhis marina fed on dried yeast: compared with algal prey
}

\author{
Eun Young Yoon ${ }^{1,2}$, Jaeyeon Park ${ }^{1, *}$, Hae Jin Jeong ${ }^{1,2}$ and Jung-Rae Rho ${ }^{3}$ \\ ${ }^{1}$ Environment and Resource Convergence Center, Advanced Institutes of Convergence Technology, Suwon 16229, Korea \\ ${ }^{2}$ School of Earth and Environmental Sciences, College of Natural Sciences, Seoul National University, Seoul 08826, Korea \\ ${ }^{3}$ Department of Marine Biotechnology, Kunsan National University, Kunsan 54150, Korea
}

The heterotrophic dinoflagellate Oxyrrhis marina is known to produce high levels of docosahexaenoic acid (DHA) when fed on diverse algal prey. However, large-scale culturing of algal prey species is not easy and requires a large amount of budget, and thus more easily cultivable and low-cost prey is required. Dried yeast was selected as a strong candidate for an alternative prey in our preliminary tests. Thus, we explored the fatty acid composition and DHA production of $O$. marina fed on dried yeast and compared these results to those of $O$. marina fed on two algal prey species: the phototrophic dinoflagellate Amphidinium carterae and chlorophyte Chlorella sp. powder. O. marina fed on dried yeast, which does not contain DHA, produced the same high level of DHA as those fed on DHA-containing A. carterae. This indicates that $O$. marina is likely to produce DHA by itself regardless of prey items. Furthermore, the DHA content (and portion of total fatty acid methyl esters) of $O$. marina satiated with dried yeast, $52.40 \mathrm{pg}$ per cell (and $25.9 \%$ ), was considerably greater than that of O. marina fed on A. carterae (26.91 pg per cell; 15.7\%) or powder of Chlorella sp. powder (21.24 pg per cell; $16.7 \%$ ). The cost of dried yeast (approximately 10 US dollars for $1 \mathrm{~kg}$ dried yeast) was much lower than that of obtaining the algal prey (approximately 160 US dollars for $1 \mathrm{~kg}$ A. carterae). Therefore, compared to conventional algal prey, dried yeast is a more easily obtainable and lower-cost prey for use in the production of DHA by O. marina.

Key Words: Amphidinium carterae; Chloroella; DHA production; feeding; lipid; low-cost prey; omega-3

\section{INTRODUCTION}

Docosahexaenoic acid (DHA) is a polyunsaturated fatty acid that belongs to the omega-3 group (Kitajka et al. 2004, Sijtsma and de Swaaf 2004, Mendes et al. 2009). Some unsaturated fatty acids such as eicosapentaenoic acid (EPA) and DHA are known to be useful materials for human health (Simopoulos 1991, Arts et al. 2001, Calder and Yaqoob 2009) as they can reduce both coronary heart disease and depression (Joordens et al. 2007). Several protists contain high levels of EPA and / or DHA (Tang and Taal 2005, Burja et al. 2006, Veloza et al. 2006, Liu et al. 2014). In particular, the heterotrophic dinoflagellate Oxyrrhis marina is known to produce high levels of DHA when fed on some algal prey (Klein Breteler et al. 1999, Veloza et al. 2006, Adolf et al. 2007, Lund et al. 2008). However, large scale culturing of algal prey is both difficult and expensive, a low-cost prey than can be easily cultivated is
(9) $\$$ This is an Open Access article distributed under the terms of the Creative Commons Attribution Non-Commercial License (http://creativecommons.org/licenses/by-nc/3.0/) which permits unrestricted non-commercial use, distribution, and reproduction in any medium, provided the original work is properly cited.

\author{
Received December 6, 2016, Accepted March 5, 2017 \\ *Corresponding Author \\ E-mail: bada0@snu.ac.kr \\ Tel: +82-31-880-9042, Fax: +82-31-880-9040
}


needed. The fatty acid composition and DHA production of $O$. marina fed on the cryptophyte Rhodomonas salina are known to be similar to those fed on the chlorophyte Dunaliella tertiolecta (Klein Breteler et al. 1999, Veloza et al. 2006), suggesting that the fatty acid composition and DHA production of $O$. marina may not be dependent on its prey. Therefore, if the fatty acid composition and DHA production of $O$. marina fed on an easily cultivated lowcost prey are similar or higher than in O. marina fed on conventional algal prey species, we can replace the latter prey with the former. O. marina is known to feed on diverse prey such as bacteria, nano- or micro-flagellates, phototrophic dinoflagellates, heterotrophic nanoflagellates, ciliates, and yeast (Droop 1959, Jeong et al. 2001, 2003, 2007, 2008, 2010, 2014, Roberts et al. 2010, Yang et al. 2011, Lee et al. 2014). While there have been several studies exploring the lipid content, fatty acid composition, and / or DHA production of O. marina fed on algal prey (Klein Breteler et al. 1999, Veloza et al. 2006, Park et al. 2016), no studies have examined O. marina fed on heterotrophic protist prey or yeast yet. As obtaining commercial dried yeast is much easier and cost effective than cultivating algal prey (Coutteau et al. 1992, Spolaore et al. 2006) or heterotrophic protist prey, it is worth investigating the fatty acid composition and / or DHA production of $O$. marina fed on yeast.

In the present study, we explored the fatty acid composition and DHA content of O. marina fed on dried yeast and compared the results with O. marina fed on Amphidinium carterae, which has a high DHA content, and powder of the chlorophyte Chlorella sp., which does not contain DHA. The results of this study provide a basis for understanding the fatty acid composition and DHA production of $O$. marina fed on yeast and algal prey items and suggest a new method for cultivating $O$. marina with high DHA levels using low-cost prey that can be easily obtainable.

\section{MATERIALS AND METHODS}

\section{Preparation of experimental organisms}

A. carterae was grown in enriched $\mathrm{f} / 2$ medium without silicate at $20^{\circ} \mathrm{C}$ and 30 salinity under a $14: 10 \mathrm{~h}$ light : dark cycle of $20 \mu \mathrm{E} \mathrm{m}^{-2} \mathrm{~s}^{-1}$ provided with the white cool fluorescent light. Dried Chlorella sp. powder was obtained from GapDang Food (Seoul, Korea) and dried yeast (Saccharomyces cerevisiae) from Red Star, Lesaffre Yeast Corporation (Milwaukee, WI, USA) (Table 1).

O. marina was isolated from a coastal water off Kunsan, Korea in May 2001 when the water temperature and salinity were $16^{\circ} \mathrm{C}$ and 27.7 , respectively. Clonal cultures of $O$. marina were maintained using $A$. carterae as prey at $20^{\circ} \mathrm{C}$ under $10 \mu \mathrm{E} \mathrm{m}^{-2} \mathrm{~s}^{-1}$ of white cool fluorescent continuous light. Cultures of $O$. marina fed on target prey item for 3-4 weeks were used for the analyses of fatty acid composition and DHA when fed on each prey.

\section{Analysis of fatty acid composition and DHA content}

The experiment was designed to investigate fatty acid composition and DHA content of O. marina fed on each of the three different prey items at the same biomass. A dense culture of $O$. marina fed with A. carterae was starved for 4-5 $\mathrm{d}$ before distributing to triplicate 10 -L polycarbonate (PC) bottles. Two liters of $A$. carterae culture at a concentration of ca. 200,000 cells $\mathrm{mL}^{-1}$ were added to each $\mathrm{PC}$ bottle containing $3 \mathrm{~L} \mathrm{O}$. marina culture, resulting in a final $O$. marina concentration in each bottle ca. 1,800 cells $\mathrm{mL}^{-1}$. These bottles were capped, placed on a shelf, and incubated at $20^{\circ} \mathrm{C}$ under a continuous illumination of $10 \mu \mathrm{E} \mathrm{m}^{-2} \mathrm{~s}^{-1}$. After 3 and $6 \mathrm{~d}, 2 \mathrm{~L}$ of $A$. carterae culture at a concentration of ca. 200,000 cells $\mathrm{mL}^{-1}$ was added as prey to each bottle again. At $7 \mathrm{~d}, 4 \mathrm{~L}$ aliquots were taken

Table 1. Strains used in this study

\begin{tabular}{|c|c|c|c|c|c|c|}
\hline Strains & Date & Area & Temperature $\left({ }^{\circ} \mathrm{C}\right)$ & Salinity & $\begin{array}{l}\text { Prey or culture } \\
\text { media }\end{array}$ & $\begin{array}{c}\text { Culture } \\
\text { temperature }\left({ }^{\circ} \mathrm{C}\right)\end{array}$ \\
\hline Oxyrrhis marina & May 2001 & Kunsan, Korea & 16.0 & 27.7 & Amphidinium carterae & 20 \\
\hline Amphidinium carterae & NA & USA & NA & NA & $\mathrm{f} / 2$-Si medium & 20 \\
\hline Chlorella sp. powder & \multicolumn{6}{|c|}{ GapDang Food, Seoul, Korea } \\
\hline Dried yeast & \multicolumn{6}{|c|}{ Saccharomyces cerevisiae, Red Star, Lesaffre Yeast Corporation, Milwaukee, WI, USA } \\
\hline
\end{tabular}

NA, not available. 
from each bottle and filtered with GF/C filters $(47 \mathrm{~mm}$ in diameter; Whatman, Kent, UK). At $7 \mathrm{~d}$, most $O$. marina cells were satiated with $A$. carterae so prey cells were not detected in the ambient waters (i.e., close to satiated condition). However, at $11 \mathrm{~d}$, ingested prey cells inside the protoplasm of $O$. marina cells were undetectable that they were in (i.e., close to starved condition). The filters were dried in the freeze dryer overnight. O. marina cells incubated with dried Chlorella sp. powder or dried yeast were obtained in the same manner described here for $A$. carterae prey.

The weight of each filter containing $O$. marina fed on one of the three different prey items was measured using a microbalance (precision of 0.0001; EL 204-IC; MettlerToledo, Columbus, OH, USA) with a blank filter used as a control. Extraction and quantification of lipids were conducted according to Bligh and Dyer (1959); each of the filters was placed in one 1-L glass bottle and then 300 $\mathrm{mL}$ chloroform-methanol $(2: 1, \mathrm{v} / \mathrm{v})$ was added. After 2-3 h sonication, $100 \mathrm{~mL}$ methanol and $180 \mathrm{~mL}$ water were added to the bottle to make a final solvent ratio of chloroform : methanol : water of $1: 1: 0.9$. The lipid-chloroform layer in the bottle was separated from the methanol-water layer using a separatory funnel and then placed in a pearshaped flask. The chloroform was evaporated in a water bath at $32^{\circ} \mathrm{C}$ using a rotary evaporator (Eyela $\mathrm{N}-1100$; Eyela-Tokyo Rikaki-Kai Co., Tokyo, Japan). The weight of the crude oils left behind (i.e., the total lipid content) was measured gravimetrically using a microbalance. Transesterification reactions where crude oils are converted to fatty acids were conducted using the modified one-step procedure (methanolic $\mathrm{HCl}$ for $2 \mathrm{~h}$ at $70^{\circ} \mathrm{C}$ ) of Sukhija and Palmquist (1988).

Fatty acid composition and DHA production were also analyzed using gas chromatography (Agilent 7890A; Agilent Technologies, Santa Clara, CA, USA). The compounds were identified in the NIST mass spectral database and quantified by comparing the peak area with that of the standard (Sigma 47885-U, Supelco 37 component FAME Mix; Supelco, Bellefonte, PA, USA).

\section{RESULTS AND DISCUSSION}

\section{Fatty acid compositions of three preys and Oxyr- rhis marina fed on each prey}

The fatty acid compositions of dried yeast, A. carterae, and Chlorella sp. powder differed from one another (Table 2, Fig. 1); the sequences of the amounts of the fatty ac- ids in the prey species were C18:1 $(23.9 \%)>\mathrm{C} 16: 1(21.4 \%)$ $>\mathrm{C} 16: 0(21.0 \%)>\mathrm{C} 18: 0(16.5 \%)>\mathrm{C} 18: 2$ (15.7\%) for dried yeast, C22:0 $(22.4 \%)>\mathrm{C} 16: 0(22.1 \%)>\mathrm{C} 18: 4(19.1 \%)>$ C22:6 (17.4\%) > C18:1 (4.6\%) for A. carterae, and C18:2 $(49.4 \%)>\mathrm{C} 17: 0(24.1 \%)>\mathrm{C} 16: 0(13.9 \%)>\mathrm{C} 16: 1(4.3 \%)$ $>$ C18:1 and C18:3 (2.2\%, respectively) for Chlorella sp. powder (Fig. 1A-C).

The fatty acid compositions of $O$. marina fed on dried yeast, A. carterae, and Chlorella sp. powder at Day 7 (satiated condition) were similar to one another (Table 3, Fig. 1). In particular, the order of the top five fatty acids in $O$. marina fed on these three prey items at Day 7 were the same; the most abundant fatty acid was C16:0 (43.4-52.5\% of total fatty acids), and C22:6 (15.7-25.9\%), C18:1c\&t (2.8-8.9\%), C12:0 (3.1-5.4\%), and C18:0 (3.7-4.8\%) followed it (Fig. 1D-F). Meanwhile, at Day 11 (starved condition), the most abundant fatty acid was $\mathrm{C} 16: 0$ (53.5-59.1\% of total fatty acids), and C18:1 (11.1-15.0\%), C22:6 (1.26.7\%), C18:0 (2.0-5.0\%), and C16:1 (1.5-4.6\%) followed it (Fig. 1G-I).

O. marina fed on dried yeast had only $2.8 \% \mathrm{C} 18: 1$ at Day 7, although the yeast had 23.9\% C18:1. Furthermore, O. marina fed on yeast, which does not produce DHA,

Table 2. Fatty acid percentage (\%) of dried yeast, Amphidinium carterae, and Chlorella sp. powder that were used as prey items for Oxyrrhis marina

\begin{tabular}{lccc}
\hline & Dried yeast & A.carterae & Chlorella sp.powder \\
\hline C10:0 & - & - & - \\
C11:0 & - & - & - \\
C12:0 & - & - & - \\
C13:0 & - & - & - \\
C14:0 & - & - & 0.9 \\
C14:1 & - & - & 0.7 \\
C15:0 & 1.4 & - & 1.0 \\
C15:1 & - & - & - \\
C16:0 & 21.0 & 22.1 & 13.9 \\
C16:1 & 21.4 & 4.1 & 4.3 \\
C17:0 & - & - & 24.1 \\
C17:1 & - & - & 1.4 \\
C18:0 & 16.5 & 3.2 & - \\
C18:1c\&t & 23.9 & 4.6 & 2.2 \\
C18:2c\&t & 15.7 & - & 49.4 \\
C18:3-n6 & - & - & 2.2 \\
C18:3-n3 & - & - & - \\
C18:4 & - & 19.1 & - \\
C20:0 & - & 2.7 & - \\
C20:1 & - & 4.5 & - \\
C20:2 & - & - & - \\
C20:5 & - & - & - \\
C22:0 & - & 22.4 & - \\
C22:1 & - & - & - \\
C23:0 & - & - & - \\
C22:6 & - & 17.4 & 100 \\
Total & 100 & 100 & \\
\hline & & & - \\
\hline
\end{tabular}



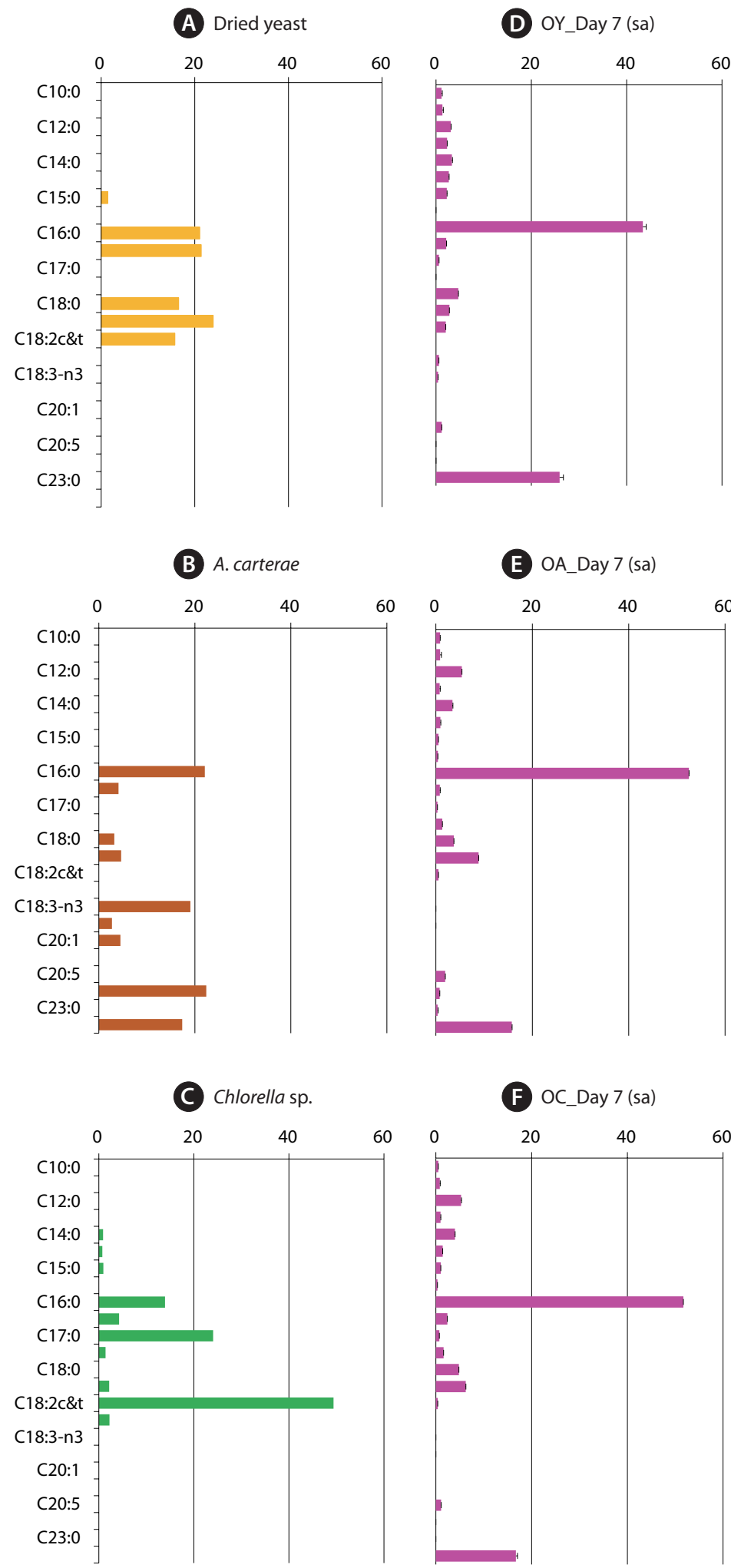
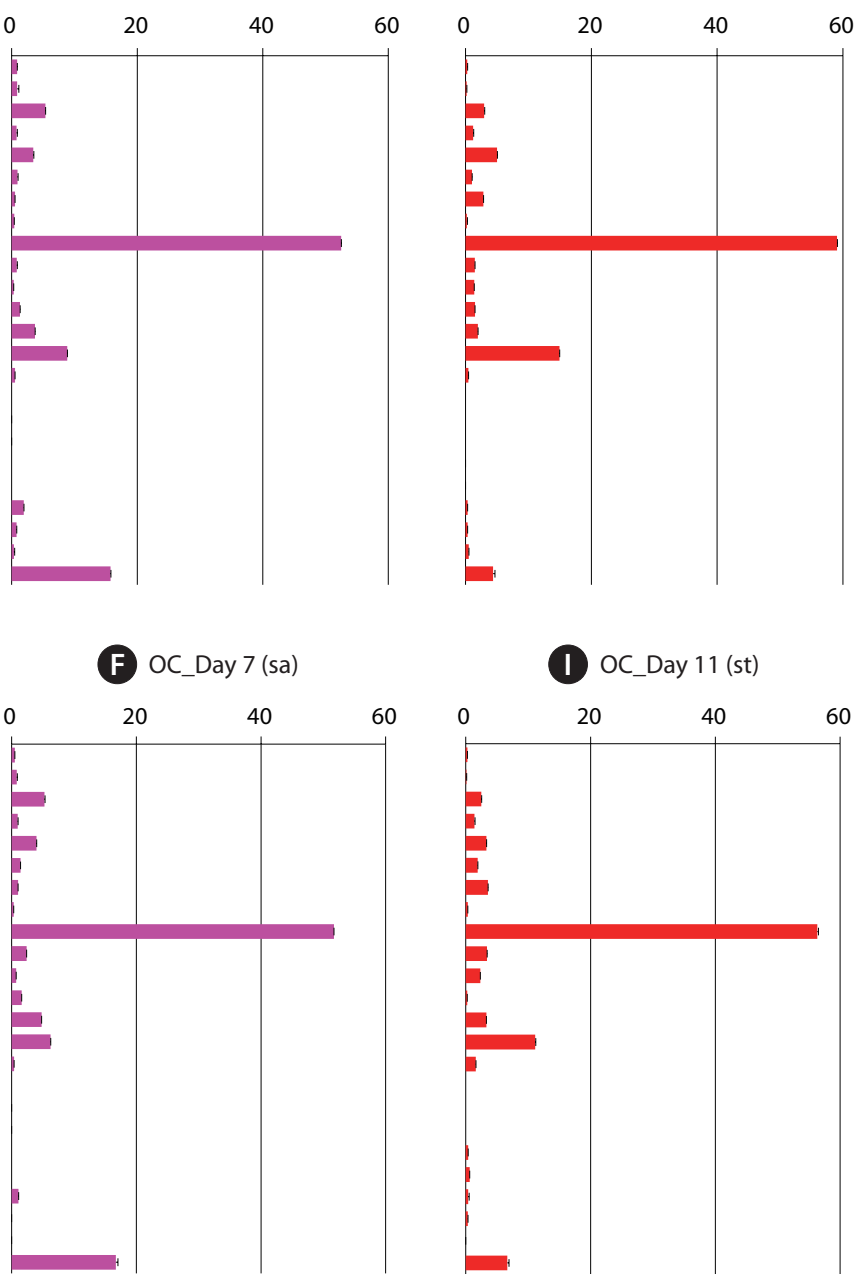

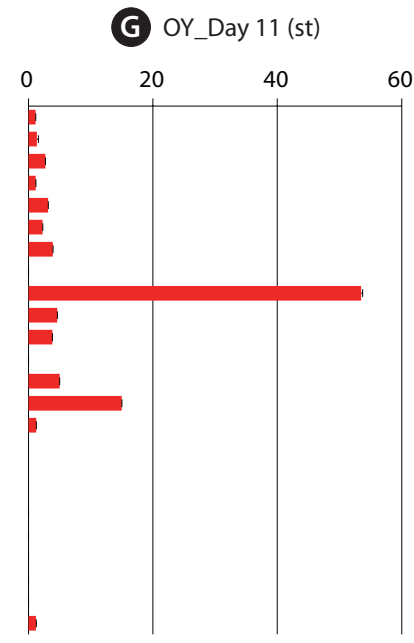

H OA_Day 11 (st)

(I) OC_Day 11 (st)

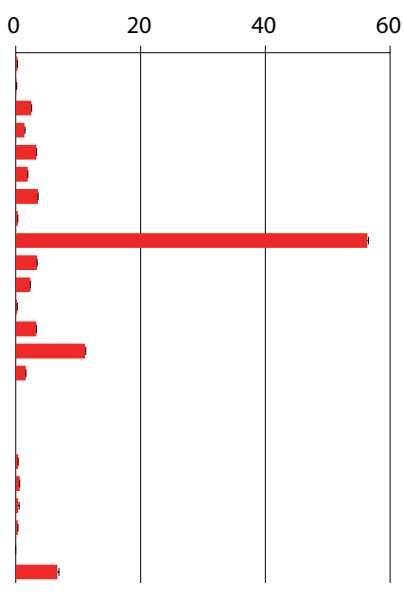

Fig. 1. Fatty acid composition as a percentage of total fatty acid methyl ester components from prey items, dried yeast (A), Amphidinium carterae (B), and Chlorella sp. powder (C) and from Oxyrrhis marina fed on each of the three prey species at Day 7 under satiated (sa) conditions (DF) and at Day 11 under starved (st) condition (G-I). OY, O. marina fed on dried yeast; OA, O. marina fed on A. carterae; OC, O. marina fed on Chlorella sp. powder. The error bars represent the standard deviation from the mean of replicate data $(n=2)$. 


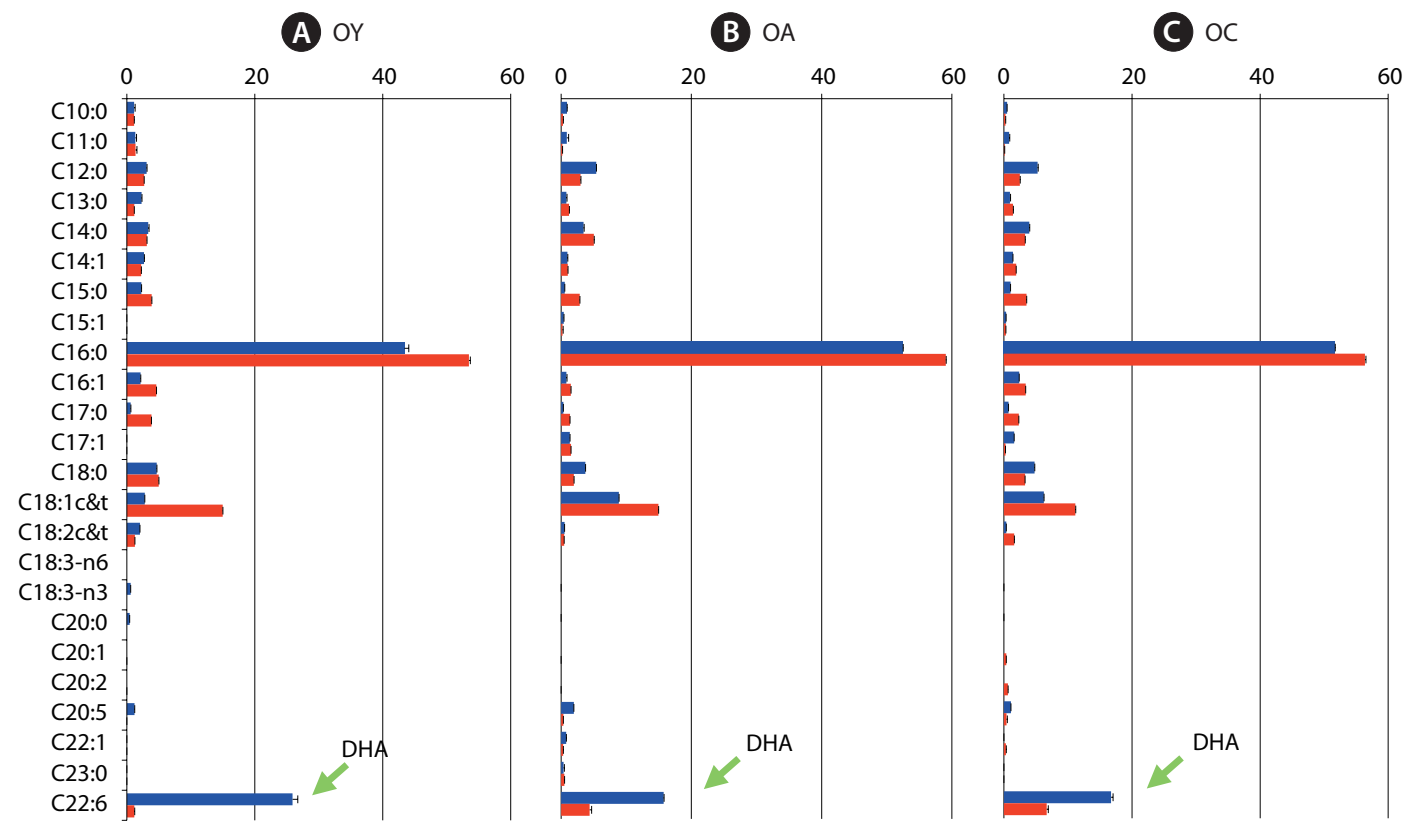

Fig. 2. Comparision of fatty acid composition as a percentage of total fatty acid methyl ester components from Oxyrrhis marina fed on the three different prey items at Day 7 (blue, satiated condition) and Day 11 (red, starved condition). (A) O. marina fed on dried yeast (OY). (B) O. marina fed on A. carterae (OA). (C) O. marina fed on Chlorella sp. powder (OC). The arrow indicates docosahexenoic acid (DHA). The error bars represent the standard deviation from the mean of replicate data $(n=2)$.

Table 3. Comparison of the fatty acid composition of Oxyrrhis marina fed with three different prey

\begin{tabular}{|c|c|c|c|c|c|c|}
\hline \multirow[b]{2}{*}{ FAME } & \multicolumn{2}{|c|}{ O. marina on dried yeast } & \multicolumn{2}{|c|}{ O. marina on A. carterae } & \multicolumn{2}{|c|}{ O. marina on Chlorella sp. powder } \\
\hline & $\begin{array}{c}\text { Day } 7 \\
\text { (satiated) }\end{array}$ & $\begin{array}{c}\text { Day } 11 \\
\text { (starved) }\end{array}$ & $\begin{array}{c}\text { Day } 7 \\
\text { (satiated) }\end{array}$ & $\begin{array}{c}\text { Day } 11 \\
\text { (starved) }\end{array}$ & $\begin{array}{c}\text { Day } 7 \\
\text { (satiated) }\end{array}$ & $\begin{array}{c}\text { Day } 11 \\
\text { (starved) }\end{array}$ \\
\hline C10:0 & $1.15 \pm 0.30$ & $1.13 \pm 0.06$ & $0.88 \pm 0.06$ & $0.27 \pm 0.12$ & $0.50 \pm 0.03$ & $0.27 \pm 0.02$ \\
\hline $\mathrm{C} 11: 0$ & $1.34 \pm 0.38$ & $1.35 \pm 0.45$ & $0.86 \pm 0.59$ & $0.18 \pm 0.07$ & $0.81 \pm 0.19$ & $0.12 \pm 0.03$ \\
\hline $\mathrm{C} 12: 0$ & $3.09 \pm 0.18$ & $2.70 \pm 0.03$ & $5.39 \pm 0.03$ & $2.96 \pm 0.13$ & $5.26 \pm 0.18$ & $2.50 \pm 0.12$ \\
\hline C13:0 & $2.31 \pm 0.10$ & $1.16 \pm 0.03$ & $0.80 \pm 0.21$ & $1.20 \pm 0.16$ & $0.96 \pm 0.16$ & $1.41 \pm 0.18$ \\
\hline $\mathrm{C} 14: 0$ & $3.33 \pm 0.25$ & $3.14 \pm 0.06$ & $3.45 \pm 0.17$ & $5.02 \pm 0.09$ & $3.99 \pm 0.08$ & $3.31 \pm 0.09$ \\
\hline C14:1 & $2.69 \pm 0.11$ & $2.25 \pm 0.04$ & $0.95 \pm 0.13$ & $1.02 \pm 0.09$ & $1.43 \pm 0.01$ & $1.91 \pm 0.03$ \\
\hline $\mathrm{C} 15: 0$ & $2.26 \pm 0.10$ & $3.89 \pm 0.06$ & $0.54 \pm 0.01$ & $2.84 \pm 0.07$ & $1.03 \pm 0.01$ & $3.55 \pm 0.06$ \\
\hline C15:1 & - & - & $0.41 \pm 0.02$ & $0.21 \pm 0.18$ & $0.33 \pm 0.01$ & $0.32 \pm 0.01$ \\
\hline C16:0 & $43.38 \pm 1.42$ & $53.49 \pm 0.44$ & $52.50 \pm 0.03$ & $59.08 \pm 0.09$ & $51.70 \pm 0.03$ & $56.35 \pm 0.34$ \\
\hline C16:1 & $2.15 \pm 0.07$ & $4.62 \pm 0.03$ & $0.80 \pm 0.19$ & $1.47 \pm 0.06$ & $2.39 \pm 0.01$ & $3.40 \pm 0.04$ \\
\hline $\mathrm{C} 17: 0$ & $0.62 \pm 0.02$ & $3.85 \pm 0.00$ & $0.33 \pm 0.02$ & $1.37 \pm 0.00$ & $0.73 \pm 0.01$ & $2.35 \pm 0.00$ \\
\hline $\mathrm{C} 17: 1$ & - & - & $1.34 \pm 0.02$ & $1.51 \pm 0.02$ & $1.60 \pm 0.00$ & $0.24 \pm 0.00$ \\
\hline C18:0 & $4.67 \pm 0.06$ & $5.00 \pm 0.04$ & $3.71 \pm 0.06$ & $1.95 \pm 0.07$ & $4.79 \pm 0.03$ & $3.30 \pm 0.04$ \\
\hline C18:1c\&t & $2.81 \pm 0.03$ & $14.98 \pm 0.09$ & $8.86 \pm 0.05$ & $14.94 \pm 0.07$ & $6.25 \pm 0.03$ & $11.14 \pm 0.13$ \\
\hline $\mathrm{C} 18: 2 \mathrm{c} \& \mathrm{t}$ & $2.05 \pm 0.02$ & $1.25 \pm 0.01$ & $0.53 \pm 0.00$ & $0.46 \pm 0.01$ & $0.39 \pm 0.00$ & $1.62 \pm 0.02$ \\
\hline C18:3-n6 & - & - & - & - & - & - \\
\hline C18:3-n3 & $0.61 \pm 0.01$ & - & - & - & - & - \\
\hline C20:0 & $0.44 \pm 0.01$ & - & - & - & - & - \\
\hline C20:1 & - & - & - & - & - & $0.39 \pm 0.02$ \\
\hline $\mathrm{C} 20: 2$ & - & - & - & - & - & $0.64 \pm 0.02$ \\
\hline C20:5 & $1.20 \pm 0.03$ & - & $1.95 \pm 0.02$ & $0.33 \pm 0.01$ & $1.10 \pm 0.03$ & $0.41 \pm 0.29$ \\
\hline $\mathrm{C} 22: 1$ & - & - & $0.79 \pm 0.03$ & $0.32 \pm 0.01$ & - & $0.32 \pm 0.09$ \\
\hline C23:0 & - & - & $0.36 \pm 0.26$ & $0.51 \pm 0.01$ & - & - \\
\hline C22:6\&C24:1 & $25.91 \pm 0.63$ & $1.18 \pm 0.12$ & $15.74 \pm 0.15$ & $4.37 \pm 0.64$ & $16.73 \pm 0.64$ & $6.67 \pm 0.51$ \\
\hline Total & 100 & 100 & 100 & 100 & 100 & 100 \\
\hline
\end{tabular}

It fed on dried yeast, Amphidinium carterae, and dried Chlorella sp. powder. Measurements were taken when the cells were satiated (Day 7) and starved (Day 11). FAME, fatty acid methyl ester. The errors represent the standard deviation from the mean of replicate data $(n=2)$. 

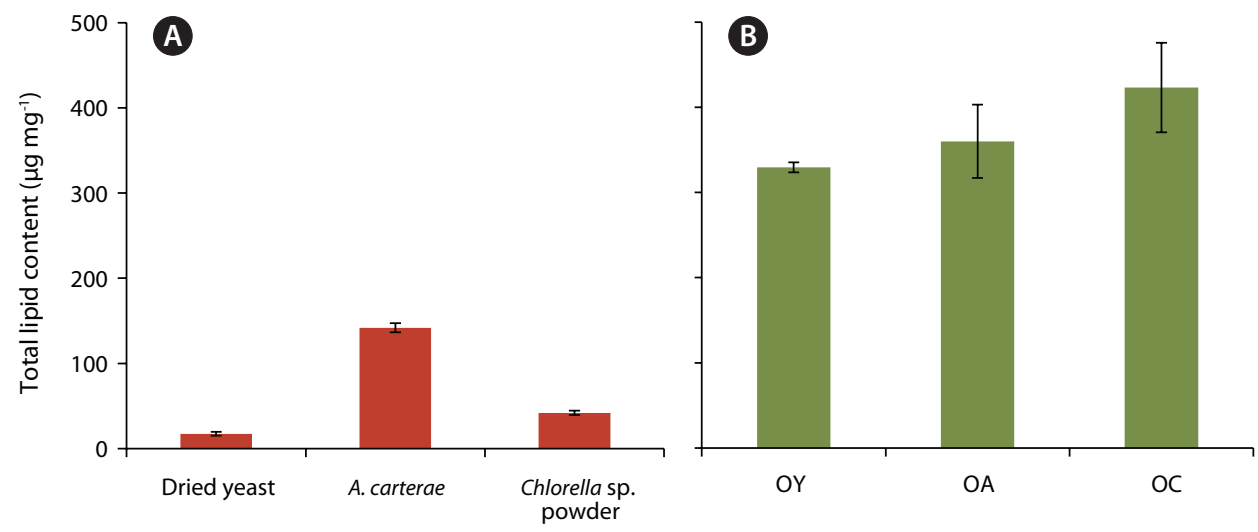

Fig. 3. Total lipid content $\left(\mu \mathrm{g} \mathrm{mg}^{-1}\right)$ of the three prey items, dried yeast, Amphidinium carterae, and Chlorella sp. powder (A) and Oxyrrhis marina fed on each prey, O. marina on dried yeast (OY), A. carterae (OA), and Chlorella sp. powder (OC) (B). The error bar represents the standard deviation from the mean of triplicate data $(n=3)$.

had 25.9\% DHA (Fig. 1A \& D). At Day 7, O. marina fed on A. carterae did not have C18:4 or C22:0 (behenic acid) even though the prey contained $19.1 \%$ C18:4 and $22.4 \%$ C22:0 (Fig. 1B \& E). Moreover, at Day 7, O. marina fed on Chlorella sp. powder had only 0.4\% C18:2 (linoleic acid) and $0.7 \% \mathrm{C} 17: 0$ (margaric acid) even though the prey had 49.4\% C18:2 and 24.1\% C17:0 (Fig. 1C \& F).

At Day 11, the proportion of DHA was dramatically decreased after the prey was completely digested (Fig. 2). $O$. marina fed on dried yeast, A. carterae and Chlorella sp. powder had 15.7-25.9\% DHA at Day 7 (satiated condition), but the proportion of DHA was decreased to 1.2$6.7 \%$ at Day 11 (starved condition) (Fig. 2A-C). In particular, when O. marina fed on dried yeast, $95 \%$ of DHA was reduced at Day 11 (Fig. 2A).

This study clearly shows that the fatty acid composition and DHA content of $O$. marina fed on dried yeast were similar to those fed on algal prey, even though the fatty acid composition and DHA content of the three different preys differed considerably. This suggests that yeast can be used for efficient DHA production in O. marina. In general, heterotrophs have a higher lipid content and higher quality fatty acid composition (i.e., EPA and DHA) than microalgae (Tang and Taal 2005, Burja et al. 2006, Veloza et al. 2006, Liu et al. 2014). However, cultivating the heterotrophs is more difficult and more expensive than cultivating microalgae because of the prey required by the heterotrophs. The cost of obtaining commercial dried yeast (approximately 10 US dollars per $\mathrm{kg}$ ) is much lower than cultivating cost of general microalgal prey such as
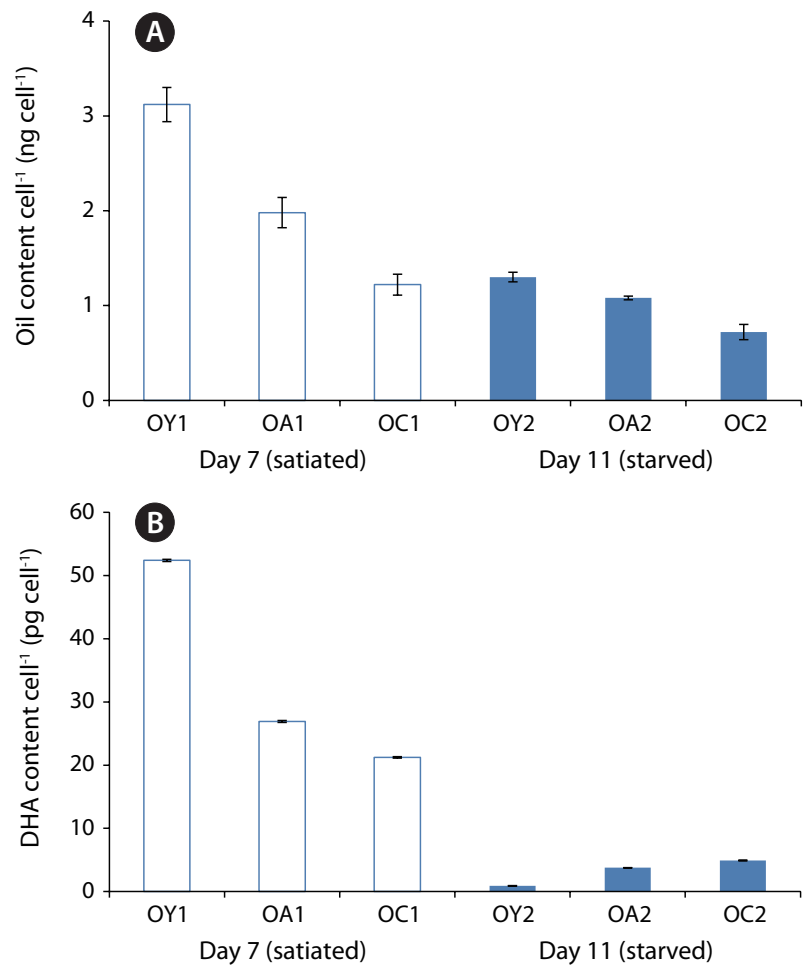

Fig. 4. Changes in the oil per cell (ng cell $\left.{ }^{-1}\right)(A)$ and docosahexenoic acid (DHA) content per cell (pg cell ${ }^{-1}$ ) (B) of Oxyrrhis marina fed on three different prey items. O. marina fed on dried yeast (OY), $A$. carterae (OA), and Chlorella sp. powder (OC) at Day 7 under satiated conditions (OY1, OA1, and OC1) and Day 11 under starved condition $(O Y 2, O A 2$, and $O C 2)$, respectively. The error bar represents the standard deviation from the mean of triplicate data $(n=3)$.

A. carterae (approximately 160 USD per kg) (Spolaore et al. 2006). Yeast, therefore, is an excellent prey for DHAproducing $O$. marina, as it is more easily cultivated and cheaper than the conventional algal prey. 


\section{Total lipid and DHA content}

The total lipid content (mean \pm SD) of dried yeast (17.3 $\pm 2.4 \mu \mathrm{g} \mathrm{mg}^{-1}$ ) was much lower than that of $A$. carterae $\left(141.8 \pm 5.5 \mu \mathrm{g} \mathrm{mg}^{-1}\right)$ or Chlorella sp. powder $(41.9 \pm 2.6 \mu \mathrm{g}$ $\left.\mathrm{mg}^{-1}\right)$ (Fig. 3A). However, the total lipid content $( \pm \mathrm{SD})$ of O. marina fed on dried yeast (329.5 $\pm 5.9 \mu \mathrm{g} \mathrm{mg}^{-1}$ ) was approximately $10-30 \%$ lower than that of $O$. marina fed on Chlorella sp. powder $\left(423.3 \pm 52.6 \mu \mathrm{g} \mathrm{mg}^{-1}\right)$ or A. carterae (360.1 \pm 43.1 ug mg $^{-1}$ ) (Fig. 3B).

The lipid content per cell of yeast-fed O. marina at Day 11 (starved conditions) was different from that at Day 7 (satiated conditions) (Fig. 4A); the DHA content of yeast-fed O. marina at Day 11 (0.90 pg per cell, 1.2\%) was much lower than that at Day 7 (52.40 pg per cell, 25.9\%); the DHA content of A. carterae-fed O. marina at Day 11 (3.78 pg per cell, $4.4 \%$ ) was also much lower than that at Day 7 (26.91 pg per cell, 15.7\%); and the DHA content of Chlorella sp.-fed O. marina fed at Day 11 (4.91 pg per cell, $6.7 \%$ ) was much lower than that at Day 7 (21.24 pg per cell, $16.7 \%$ ) (Fig. 4B). As the DHA content of O. marina satiated with yeast was greater at Day 7 than at Day 11, harvesting $O$. marina cells fed on dried yeast every $7 \mathrm{~d}$ result in higher DHA production than with longer harvesting intervals in this experiments.

\section{CONCLUSION}

This study demonstrated that the fatty acid composition and DHA content of $O$. marina fed on dried yeast are comparable to O. marina fed on algal prey (A. carterae or dried powders of Chlorella sp.), despite the fact that the fatty acid composition and DHA content of the three different prey items differ considerably. Thus, dried yeast which is both easily obtainable and cheap is an excellent prey for DHA production in O. marina. The DHA content of $O$. marina was greatest when they satiated, suggesting that harvesting $O$. marina cells satiated with dried yeast may result in higher DHA production than harvesting $O$. marina starved.

\section{ACKNOWLEDGEMENTS}

This research was supported by developing the method of converting food wastes to bioenergy using mass cultured marine protozoa, and Management of marine organisms causing ecological disturbance and harmful effect Program of Korea Institute of Marine Science and
Technology Promotion (KIMST) award to J. Park, and Useful Dinoflagellate program of KIMST award to HJJ. We thank Seung Joo Moon for technical support.

\section{REFERENCES}

Adolf, J. E., Krupatkina, D., Bachvaroff, T. \& Place, A. R. 2007. Karlotoxin mediates grazing by Oxyrrhis marina on strains of Karlodinium veneficum. Harmful Algae 6:400412.

Arts, M. T., Ackman, R. G. \& Holub, B. J. 2001. "Essential fatty acids" in aquatic ecosystems: a crucial link between diet and human health and evolution. Can. J. Fish. Aquat. Sci. 58:122-137.

Bligh, E. G. \& Dyer, W. J. 1959. A rapid method of total lipid extraction and purification. Can. J. Biochem. Physiol. 37:911-917.

Burja, A. M., Radianingtyas, H., Windust, A. \& Barrow, C. J. 2006. Isolation and characterization of polyunsaturated fatty acid producing Thraustochytrium species: screening of strains and optimization of omega-3 production. Appl. Microbiol. Biotechnol. 72:1161-1169.

Calder, P. C. \& Yaqoob, P. 2009. Understanding omega-3 polyunsaturated fatty acids. Postgrad. Med. 121:148-157.

Coutteau, P., Brendonck, L., Lavens, P. \& Sorgeloos, P. 1992. The use of manipulated baker's yeast as an algal substitute for the laboratory culture of Anostraca. Hydrobiol. 234:25-32.

Droop, M. R. 1959. A note on some physical conditions for cultivating Oxyrrhis marina. J. Mar. Biol. Assoc. U. K. 38:599-604.

Jeong, H. J., Kang, H., Shim, J. H., Park, J. K., Kim, J. S., Song, J. Y. \& Choi, H. -J. 2001. Interactions among the toxic dinoflagellate Amphidinium carterae, the heterotrophic dinoflagellate Oxyrrhis marina, and the calanoid copepods Acartia spp. Mar. Ecol. Prog. Ser. 218:77-86.

Jeong, H. J., Kim, J. S., Yoo, Y. D., Kim, S. T., Kim, T. H., Park, M. G., Lee, C. H., Seong, K. A., Kang, N. A. \& Shim, J. H. 2003. Feeding by the heterotrophic dinoflagellate Oxyrrhis marina on the red-tide raphidophyte Heterosigma akashiwo: a potential biological method to control red tides. J. Eukaryot. Microbiol. 50:274-282.

Jeong, H. J., Lim, A. S., Yoo, Y. D., Lee, M. J., Lee, K. H., Jang, T. Y. \& Lee, K. 2014. Feeding by heterotrophic dinoflagellates and ciliates on the free-living dinoflagellate Symbiodinium sp. (Clade E). J. Eukaryot. Microbiol. 61:27-41.

Jeong, H. J., Seong, K. A., Yoo, Y. D., Kim, T. H., Kang, N. S., Kim, S., Park, J. Y., Kim, J. S., Kim, G. H. \& Song, J. Y. 2008. Feeding and grazing impact by small marine heterotro- 
phic dinoflagellates on heterotrophic bacteria. J. Eukaryot. Microbiol. 55:271-288.

Jeong, H. J., Song, J. E., Kang, N. S., Kim, S., Yoo, Y. D. \& Park, J. Y. 2007. Feeding by heterotrophic dinoflagellates on the common marine heterotrophic nanoflagellate Cafeteria sp. Mar. Ecol. Prog. Ser. 333:151-160.

Jeong, H. J., Yoo, Y. D., Kim, J. S., Seong, K. A., Kang, N. S. \& Kim, T. H. 2010. Growth, feeding, and ecological roles of the mixotrophic and heterotrophic dinoflagellates in marine planktonic food webs. Ocean Sci. J. 45:65-91.

Joordens, J. C. A., Kuipers, R. S. \& Muskiet, F. A. J. 2007. Preformed dietary DHA: the answer to a scientific question may in practice become translated to its opposite. Am. J. Hum. Biol. 19:582-584.

Kitajka, K., Sinclair, A. J., Weisinger, R. S., Weisinger, H. S., Mathai, M., Jayasooriya, A. P., Halver J. E. \& Puskás, L. G. 2004. Effects of dietary omega-3 polyunsaturated fatty acids on brain gene expression. Proc. Natl. Acad. Sci. 101:10931-10936.

Klein Breteler, W. C. M., Schogt, N., Baas, M., Schouten, S. \& Kraay, G. W. 1999. Trophic upgrading of food quality by protozoans enhancing copepod growth: role of essential lipids. Mar. Biol. 135:191-198.

Lee, K. H., Jeong, H. J., Yoon, E. Y., Jang, S. H., Kim, H. S. \& Yih, W. 2014. Feeding by common heterotrophic dinoflagellates and a ciliate on the red-tide ciliate Mesodinium rubrum. Algae 29:153-163.

Liu, Y., Tang, J., Li, J., Daroch, M. \& Cheng, J. J. 2014. Efficient production of triacylglycerols rich in docosahexaenoic acid (DHA) by osmo-heterotrophic marine protists. Appl. Microbiol. Biotechnol. 98:9643-9652.

Lund, E. D., Chu, F. -L. E., Harvey, E. \& Adolf, R. 2008. Mechanism(s) of long chain n-3 essential fatty acid production in two species of heterotrophic protists: Oxyrrhis marina and Gyrodinium domains. Mar. Biol. 155:2336.
Mendes, A., Reis, A., Vasconcelos, R., Guerra, P. \& da Silva, T. L. 2009. Crypthecodinium cohnii with emphasis on DHA production: a review. J. Appl. Phycol. 21:199-214.

Park, J., Jeong, H. J., Yoon, E. Y. \& Moon, S. J. 2016. Easy and rapid quantification of lipid contents of marine dinoflagellates using the sulpho-phospho-vanillin method. Algae 31:391-401.

Roberts, E. C., Wootton, E. C., Davidson, K., Jeong, H. J., Lowe, C. D. \& Montagnes, D. J. S. 2010. Feeding in the dinoflagellate Oxyrrhis marina: linking behaviour with mechanisms. J. Plankton Res. 33:603-614.

Sijtsma, L. \& de Swaaf, M. E. 2004. Biotechnological production and applications of the $\omega-3$ polyunsaturated fatty acid docosahexaenoic acid. Appl. Microbiol. Biotechnol. 64:146-153.

Simopoulos, A. P. 1991. Omega-3 fatty acids in health and disease and in growth and development. Am. J. Clin. Nutr. 54:438-463.

Spolaore, P., Joannis-Cassan, C., Duran, E. \& Isambert, A. 2006. Commercial applications of microalgae. J. Biosci. Bioeng. 101: 87-96.

Sukhija, P. S. \& Palmquist, D. L. 1988. Rapid method for determination of total fatty acid content and composition of feedstuffs and feces. J. Agric. Food Chem. 36:1202-1206.

Tang, K. W. \& Taal, M. 2005. Trophic modification of food quality by heterotrophic protists: species-specific effects on copepod egg production and egg hatching. J. Exp. Mar. Biol. Ecol. 318:85-98.

Veloza, A. J., Chu, F. L. E. \& Tang, K. W. 2006. Trophic modification of essential fatty acids by heterotrophic protists and its effects on the fatty acid composition of the copepod Acartia tonsa. Mar. Biol. 148:779-788.

Yang, Z., Jeong, H. J. \& Montagnes, D. J. S. 2011. The role of Oxyrrhis marina as a model prey: current work and future directions. J. Plankton Res. 33:665-675. 